\title{
O INDICE DE DESENVOLVIMENTO DA EDUCAÇÃO BÁSICA E A ORGANIZAÇÃO DA ESCOLA: LIMITES E POSSIBILIDADES
}

\author{
Maria Ângela Oliveira de Sá Rubini, Alberto Albuquerque Gomes \\ Universidade Estadual Paulista - UNESP, Programa de Pós-Graduação em Educação, Presidente Prudente, SP. E-mail: \\ angela.rubini@yahoo.com.br
}

\begin{abstract}
RESUMO
Este trabalho teve como objetivo identificar e analisar os efeitos do IDEB na organização de uma escola da rede municipal de Presidente Prudente que atende séries iniciais do ensino fundamental. Para tanto adotamos a abordagem de natureza qualitativa e para a coleta de dados a entrevista semiestruturada. Os resultados demonstraram que a Prova Brasil e a divulgação do IDEB influenciam na organização da escola. Para os sujeitos entrevistados o IDEB surge como um direcionador do trabalho pedagógico. É um referencial que subsidia o planejamento das atividades cotidianas e também a análise dos conhecimentos apropriados ou não pelos alunos. Se por um lado a Prova Brasil e o IDEB são políticas profícuas às disciplinas que se circunscrevem, por outro lado impacta de maneira negativa ao gerar tensão e ansiedade em docentes e discentes uma vez que o escopo é aumentar ou manter o índice previsto pelo INEP.
\end{abstract}

Palavras-chave: Educação, Avaliação em larga escala, IDEB, Organização escolar, INEP.

\section{THE INDEX OF DEVELOPMENT OF BASIC EDUCATION AND THE SCHOOL ORGANIZATION: LIMITS AND POSSIBILITIES}

\begin{abstract}
This study aimed to identify and analyze the effects of IDEB in the organization of an elementary municipal school in Presidente Prudente. So, qualitative research and semi-structured interview were adopted as data collection tools. The results demonstrated that "Prova Brasil" and the dissemination of IDEB influence the organization of the school. For the subjects interviewed IDEB appears as a conductor of the pedagogical work. It is a reference that subsidizes the planning of daily activities and also the analysis of the knowledge seized or not by the students. If, on the one hand, "Prova Brazil" and IDEB are profitable policies to the disciplines that are circumscribed, on the other hand they impact negatively by generating tension and anxiety in teachers and students since the scope is to increase or maintain the index anticipated by INEP.
\end{abstract}

Keywords: Education, Large-scale evaluation, IDEB, School organization, INEP. 


\section{INTRODUÇÃO}

O presente trabalho tem como tema central a avaliação em larga escala e suas implicações na organização do trabalho escolar, assunto que ganha a centralidade no debate sobre políticas públicas educacionais ao dar visibilidade a interesses antagônicos emergentes na sociedade. De um lado, temos os defensores da escola pública, democrática e de qualidade, que denunciam, com fortes evidências empíricas, o impacto que as políticas de responsabilização causam aos professores e estudantes e, de outro lado, os reformadores empresariais ${ }^{1}$ oferecendo, por meio de um controle ideológico, a "cura" às deficiências na educação alinhando o trabalho pedagógico aos princípios do mundo empresarial (RAVITCH, 2011).

A nova ordem política e econômica mundial da década de 1990 coloca a educação como um setor estratégico para alavancar o desenvolvimento e a modernidade. O domínio da leitura e da escrita deixa de ser privilégio de poucos e passa a ser pré-requisito para o desenvolvimento das habilidades de acesso a outras linguagens como as tecnológicas e artísticas. Essas novas demandas de produção, de acordo com Mello (1997, p.33), “[...] remetem para a escola a responsabilidade de propiciar um sólido domínio dos códigos instrumentais da Linguagem, da Matemática e dos conteúdos científicos". Sendo assim, em contraposição a uma grande diversidade de conteúdos pouco aprofundados, prioriza-se disciplinas básicas que capacitem os sujeitos para o domínio de conhecimentos específicos e desenvolvam habilidades cognitivas que thes permitam entender as novas situações solucionando os problemas.

No contexto de redemocratização, o Brasil sinalizou reformas educacionais asseguradas pela Constituição de 1988 e reforçadas na década de 1990 pelo acordo assumido na Conferência de Educação para Todos (1990), realizada em Jomtien na Tailândia. Essa Conferência liderada por agências internacionais, como a Organização das Nações Unidas para a Educação, a Ciência e a Cultura (UNESCO), pelo Programa das Nações Unidas para o Desenvolvimento (PNUD), pelo Fundo das Nações Unidas para a infância (UNICEF) e pelo Banco Mundial (BM), resultou em diretrizes que explicitam a vinculação entre a economia e a educação no combate à pobreza, propondo o aumento da produtividade do trabalho e melhorando as condições de vida da população no mundo globalizado.

Dentre as metas firmadas, o Brasil se comprometeu a universalizar o ensino básico e a reduzir as taxas de analfabetismo, garantindo os conhecimentos básicos necessários à vida contemporânea sendo esta condição necessária para o advento de uma sociedade menos desigual e mais justa. Para que essas metas alcançassem sucesso, o Banco Mundial orientou que a educação básica, fosse prioridade, com atenção voltada aos resultados por meio da implementação de sistemas de avaliação. (SILVA e ABREU, 2008).

Em 1990, consolidou-se o Sistema de Avaliação da Educação Básica (SAEB), e alguns anos mais tarde sua organização formal se deu por meio da Portaria Ministerial no 1.795 (BRASIL, 1994). De 1990 a 2002, o SAEB foi utilizado pelo governo federal como instrumento de avaliação da educação básica do país, inicialmente, com desenho amostral, depois evoluindo para uma amostragem também censitária.

Em 2005, o SAEB passou por reestruturação e o MEC instituiu a Prova Brasil, avaliação censitária que aponta os resultados do ensino na escola e do sistema a qual pertence, conforme adesão voluntaria dos municípios e estados. (BONAMINO, 2013).

A Prova Brasil é aplicada bianualmente, envolvendo os alunos do 4 á série/5으 ano e $8^{a}$ série/9o ano do Ensino Fundamental por adesão voluntaria das redes municipais, estaduais e federais e tem por objetivo proporcionar aos gestores das políticas educacionais dados sobre o ensino público ministrado aos alunos, auxiliando na formulação e reformulação de ações e contribuindo com o direcionamento dos recursos para a melhoria da qualidade do ensino

\footnotetext{
${ }^{1}$ Termo utilizado por Ravitch (2011) nos EUA, e adotado por Freitas, L. (2012) no Brasil, reflete a aliança entre políticos, empresários, mídia, institutos, fundações etc., que defendem a iniciativa privada como proposta mais adequada para a solução dos problemas educacionais. 
ofertado. Entretanto, de importante instrumento de gestão da educação, os resultados das avaliações passam a ser associados às políticas de responsabilização e recaem sobre os profissionais da educação.

Em 2007, o Instituto Nacional de Estudos e Pesquisas Educacionais Anísio Teixeira (INEP) criou o Índice de Desenvolvimento da Educação Básica (IDEB) que reúne em um só indicador o fluxo escolar (aprovação/reprovação e evasão) e o desempenho nas avaliações (SAEB e Prova Brasil), que são exames padronizados aplicados para se obter a proficiência em Língua Portuguesa e Matemática. O IDEB é considerado referência de qualidade do ensino ofertado, é instrumento de acompanhamento das metas estabelecidas pelo Plano de Desenvolvimento da Educação (PDE) que prevê a média de 6.0, em 2022. A média nacional em 2005 era de 3.8; desta data foram estabelecidas escalas de valores bienais calculados de 0 a 10 baseados nos indicadores dos países que fazem parte da Organização para a Cooperação e Desenvolvimento Econômico (OCDE).

Diante das profundas mudanças pelas quais vem passando a educação, especificamente a educação pública brasileira, buscar compreender os princípios das reformas nos campos econômico, político e educacional é fundamental para aclarar quem somos nós educadores e o que queremos para a educação pública? No processo de globalização mundial a educação ganha papel de destaque na visão de economistas que enxergam nesse setor os futuros trabalhadores esperados nas empresas. Sendo assim, o objetivo desta pesquisa foi identificar e analisar os reflexos da Prova Brasil e do IDEB na organização de uma escola municipal em Presidente Prudente.

\section{METODOLOGIA}

Consideramos de fundamental importância compreender como pensam, o que dizem e como agem os profissionais da educação diante da política nacional de avaliação externa, mais especificamente, a Prova Brasil e o IDEB.

O presente trabalho se encaminhará pelo campo da pesquisa qualitativa. Essa escolha encontra respaldo nas afirmações de Lüdke e André $(1986$, p. 7) ao apontarem que no processo de construção das ciências sociais as abordagens qualitativas surgem para responder às questões que emergem pelos atuais desafios no campo educacional, "[...] fortemente influenciadas por uma nova atitude de pesquisa, que coloca o pesquisador no meio da cena investigada [...]." A pesquisa qualitativa possibilita ao pesquisador, o registro de dados de forma minuciosa, considerando que nada é trivial e que todos os dados permitirão a compreensão mais clara do objeto de estudo.

Para a coleta de dados da pesquisa qualitativa, utilizamos como instrumento a entrevista semiestruturada. Os sujeitos da pesquisa foram os gestores (diretor e orientadora pedagógica), uma docente de cada série $\left(1 \circ, 2 \circ, 3^{\circ}\right.$ ㅇ e 4 anos) e duas docentes dos $5 \circ$ o anos de uma escola municipal de Presidente Prudente, que atende da Educação Infantil ao 5o ano do Ensino Fundamental, localizada na zona leste, bairro de alta exclusão social.

Para Lüdke e André (1986), a entrevista representa um dos instrumentos básicos para a coleta de dados na pesquisa qualitativa desempenhando importante papel. Para as autoras, na entrevista a relação que se cria é de interação recíproca entre entrevistador e entrevistado.

\section{RESULTADOS}

Para Gatti (2013) o que tem se observado é que o IDEB passou a modelar o currículo educacional com foco nos resultados de rendimentos dos alunos nas duas áreas que se circunscrevem: língua portuguesa e matemática. Não se põe em discussão como são realizadas essas avaliações em relação as suas finalidades na educação básica. A autora afirma que: "Se, em seu inicio essas avaliações eram apresentadas como apenas diagnósticas, elas passaram a ser tomadas como grande política de currículo educacional [...]. (GATTI, 2013, p. 59). 
Os sujeitos entrevistados demonstraram concepções diferenciadas a respeito da Prova Brasil e do IDEB. Embora todos tenham afirmado que essas políticas são positivas porque evidenciam dados que convergem para a qualidade do ensino desenvolvido na escola, os mesmos apontam aspectos negativos. Um limitador apontado pelos entrevistados é a ausência de articulação entre os formuladores das políticas educacionais e os profissionais da educação que estão na escola. Os gestores afirmam que a iniciativa em desenvolver ações a partir da divulgação dos resultados do IDEB, parte exclusivamente da escola, desta forma, professores de uma universidade da cidade contribuem com a formação continuada em serviço, abordando temas relacionados às disciplinas contempladas na Prova.

As matrizes de referência da Prova Brasil direcionam o planejamento cotidiano; é a partir dos resultados que os docentes analisam e elencam os aspectos que precisam ser melhor trabalhados. Esse estudo resultou na criação de um sistema de avaliação próprio da escola, o Sistema de Avaliação do Rendimento Escolar. O SAREF foi construído pelo coletivo com o objetivo de diagnosticar os pontos frágeis no processo de ensino aprendizagem dos alunos do 1음 ao ano da escola; ele é aplicado com regularidade, sendo assim, as avaliações são o foco central na organização do planejamento escolar. Os gestores planejam o estudo semanal a partir do diagnóstico dos pontos que precisam de maior atenção em sala de aula atendendo desta forma, a necessidade de superação da defasagem dos alunos.

A ênfase na Prova Brasil e a preocupação em não deixar diminuir o índice de desempenho da escola, causam uma tensão cotidiana entre docentes e alunos, principalmente nas salas do 50 ano. Há nas falas das docentes a queixa da sobrecarga de metas a serem cumpridas, independente das dificuldades peculiares de cada aluno. Para elas o ideal seria trabalhar com mais calma, atendendo individualmente cada aluno, ajudando na superação das defasagens. Não sendo possível, a sensação que elas têm é de um trabalho superficial, raso, sem aprofundamento, haja vista a quantidade de conteúdos a serem contemplados durante os bimestres. Cada aluno tem ritmo próprio que necessitaria ser atendido e alguns aspectos como: as salas de aulas numerosas, os descritores solicitados na Prova e os projetos externos enviados pela Secretária de Educação para que a escola desenvolva, contribuem para o mal estar principalmente entre professoras e alunos dos anos finais.

Por fim, outro fator limitador, diz respeito ao ponto de largada no processo de escolarização do aluno. Os sujeitos entrevistados relatam que nem todas as famílias inserem seus filhos na escola apenas com interesse no processo de ensino aprendizagem. Dentre outros, os motivos são: os diversos recursos sociais que a permanência na escola propiciam, a proteção e ordem judicial. Sendo assim, o aprendizado não é prioridade dessas famílias e esses aspectos são abstraídos pelas crianças que demonstram e argumentam justificando o desinteresse pelos estudos.

Como possibilidade para a realização de um trabalho de qualidade, evidenciou-se que a união e o trabalho em equipe potencializam as ações de sucesso. Embora situada num bairro de alta vulnerabilidade e exclusão social, a escola vem empreendendo práticas de superação aos desafios cotidianos. Nas duas últimas edições da Prova Brasil, a escola avançou no índice superando a meta estipulada pelo INEP. (2013 IDEB 6.3 - meta projetada 6.1/ 2015 IDEB 6.4 meta projeta 6.3). (INEP 2017).

\section{DISCUSSÃO}

Nos últimos anos, as experiências com as avaliações em larga escala têm levado diversos pesquisadores a se posicionarem de maneira crítica sobre aspectos que impactam de maneira negativa nas práticas cotidianas na escola. Para Freitas (2013), são muitas as críticas à avaliação da educação básica no Brasil. Destacaremos aqui o posicionamento da autora com relação à padronização da qualidade estabelecida no IDEB. Ao considerar a média de desempenho dos 
estudantes nas duas disciplinas (língua portuguesa e matemática) avaliadas na Prova Brasil, defende-se que esse é o padrão mínimo a assegurar como direito de todos. "Há nessa escolha a pretensão de definir o que é mais importante para todos" (FREITAS, 2013, p. 87). Então, passar de ano na escola com bons resultados torna-se primordial e todos os esforços devem convergir para esse objetivo.

Há nessa escolha a ideia de que o padrão de qualidade pode ser alcançado universalmente, apesar das desigualdades regionais, diferentes experiências, do ponto de partida de cada um, das diversidades culturais etc. As diferentes realidades sociais imprimem as reais necessidades educacionais, portanto, o padrão de qualidade tem a ver com as diferenças e esse aspecto precisa ser considerado. $O$ fato do acesso ao ensino sistematizado ser oportunizado não altera o ponto de partida da escolarização para muitos indivíduos e essa realidade, não rara, no Brasil demanda mais tempo no processo formativo e toda uma organização num atendimento pedagógico peculiar que vá ao encontro das necessidades para a superação das defasagens.

Os dados gerados pela avaliação externa informam a escola sobre o seu posicionamento no ranking em relação a outras escolas, redes escolares, municípios e estados. Para a autora é preciso que efetivamente gestores, docentes e alunos se envolvam em todo o processo e que as informações sejam traduzidas, apropriadas e replanejadas pelos mesmos.

\section{CONCLUSÃO}

É diante da complexidade da sociedade atual com todos os impactos que incidem sobre a escola que ela é chamada a responder aos novos desafios da realidade econômica mundial. Essas respostas tem se concretizado em associações de matrizes de referência dos exames nacionais à qualidade da educação, deixando de lado aspectos relevantes como a valorização de uma educação como apropriação da cultura, melhoria do processo de trabalho escolar e das condições de trabalho no chão da escola.

Frente ao até aqui exposto, percebemos que a Prova Brasil e as metas estipuladas para o IDEB da escola, influenciam na organização do trabalho escolar. Talvez sem saber - pois em nenhum momento abordaram os acordos internacionais que condicionam a economia à educação - por não conhecerem as origens das políticas de avaliação, fato é que os profissionais da educação reproduzem o ideário capitalista de princípio neoliberal ao adotarem como eixo norteador do trabalho diário, os descritores das avaliações externas. Com o discurso que a Base Curricular exige o mínimo, a escola se organiza para obter boa média nos testes, criando seu próprio sistema interno de avaliação e reproduzindo as metas que se alinham aos ideais das agências multilaterais. Seria positivo se as avaliações externas fossem usadas apenas como instrumento de diagnóstico dos pontos frágeis e fortes do aprendizado dos alunos.

Acreditamos que essas questões precisam ser refletidas, debatidas e compreendidas sabendo-se que essas avaliações externas gestadas no bojo dos princípios neoliberais, são vivenciadas em terreno preconizado pela Constituição Federal de 1988 como espaço de gestão democrática. Não nos colocamos contra a avaliação externa, mas não podemos nos acomodar frente aos ideais que consubstanciam as políticas de avaliação em larga escala. A questão pela qual lutamos é pela compreensão "[...] da avaliação enquanto instrumento de apreciação do quefazer de sujeitos críticos a serviço, por isso mesmo, da libertação e não da domesticação." (FREIRE, 1996, p. 116).

\section{REFERÊNCIAS}

BONAMINO, A. M. C. de. Avaliação Educacional no Brasil 25 Anos Depois: Onde Estamos? In: BAUER, A.; GATTI, B. A. Vinte e Cinco Anos de Avaliação de Sistemas Educacionais no Brasil Implicações nas Redes de Ensino, no Currículo e na Formação de Professores. Florianópolis: Insular, 2013. (Ciclo de Debates, v. 2). 
BRASIL. Constituição (1988). Constituição da República Federativa do Brasil: promulgada em 5 de outubro de1988. São Paulo: Imprensa Oficial do Estado, 1990.

. Ministério da Educação e do Desporto. Portaria no 1.795, de 27 de dezembro de 1994. Cria o Sistema Nacional de Avaliação da Educação Básica. Diário Oficial da República Federativa do Brasil. Brasília, DF, n. 246, seção1, p. 20.767-20.768, 28 de dez. 1994.

FREIRE, P. Pedagogia da Autonomia: saberes necessários à prática educativa. São Paulo: Paz e Terra, 1996. (Coleção Leitura).

FREITAS, D. N. T. de. Avaliação da Educação Básica no Brasil: características e pressupostos. In: BAUER, A.; GATTI, B. A.; TAVARES, M., R. Vinte e Cinco Anos de Avaliação de Sistemas Educacionais no Brasil - Origem e Pressupostos. Ciclo de Debates. Florianópolis: Insular, 2013. v. 1.

FREITAS, L. C. de. Dossiê: "Políticas Públicas de Responsabilização na Educação". Educ. Soc., Campinas, v. 33, n. 119, p. 345-351, abr./jun. 2012. Disponível em: $<$ http://www.scielo.br/scielo.php?script=sci_arttext\&pid=S0101-73302012000200002>. Acesso em: 01/08/2017.

GATTI, B. A. Possibilidades e fundamentos de avaliações em larga escala: primórdios e perspectivas contemporâneas. In: BAUER, A.; GATTI, B. A.; TAVARES, M., R. Vinte e Cinco Anos de Avaliação de Sistemas Educacionais no Brasil - Origem e Pressupostos. Florianópolis: Insular, 2013. (Ciclo de Debates, v. 1).

INEP. Instituto Nacional de Estudos e Pesquisas Educacionais Anísio Teixeira. Disponível em: http://www.inep.gov.br/ Acesso em: 01/08/2017.

LÜDKE, M.; ANDRÉ, M. E. D. A. Pesquisa em educação: abordagens qualitativas. São Paulo: EPU, 1986.

MELLO, G. N. de. Cidadania e Competitividade: desafios educacionais do terceiro milênio. 6. ed. São Paulo: Cortez, 1997.

RAVITCH, D. Vida e morte do grande sistema escolar americano: como os testes padronizados e o modelo de mercado ameaçam a educação. Porto Alegre: Sulina, 2011.

SILVA, M. R.; ABREU, C. B. de M. Reformas para que? As políticas educacionais nos anos de 1990, o "novo projeto de formação" e os resultados das avaliações nacionais. Perspectiva, Florianópolis, v. 26, n. 2, p. 523-550, jul./dez. 2008. Disponível em: <http://www.perspectiva.ufsc.br>. Acesso em: $01 / 08 / 2017$. 